\title{
Práxis e Phrónesis em Paul Ricoeur
}

\section{Praxis and Phronesis in Paul Ricouer}

\author{
Profa. Dra. Constança Marcondes Cesar \\ cmarcondescesar@msn.com \\ Universidade Federal de Sergipe
}

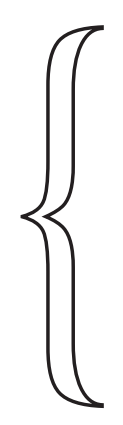

Examinaremos como Ricoeur, em sua ético-antropologia, se apropria dos conceitos de praxis e phronesis, mostrando o estreito laço que se estabelece entre eles na tradição antiga. Veremos também como se dá o diálogo do autor francês com a reflexão contemporânea e com a tradição filosófica, para formular sua filosofia da ação e do homem capaz.

PALAVRAS-CHAVE Ricoeur; Aristóteles; Práxis; Phronesis

We will examine Ricoeur's ethico-anthropology, and his appropriation of the concepts of práxis and of phrónesis, when he shows the liaison between this words as it appears on the ancient tradition of Philosophy. We will also to study how the French philosopher dialog with the contemporary philosophy and with the philosophical tradition, in order to formulate its philosophy of action and of the man's capabilities.

KEY-WORDS Ricoeur; Aristotle; Práxis; Phrónesis 


\section{Introdução}

Na obra de Ricoeur, os termos práxis e phrónesis, hauridos na tradição grega, sobretudo em Aristóteles, aparecem estreitamente ligados. Na sua meditação, essencialmente ética, a respeito do problema da ação, as ideias de sabedoria prática e prudência aparecem em primeiro plano. Uma breve consulta a dicionários de termos gregos mostra a noção de práxis - ação, atividade - associada às ideias de exercício, realização, condução de um assunto, modo de ser, conduta, destino ${ }^{1}$. Em Aristóteles, representa a escolha deliberada, com implicações morais. Move-se no âmbito das ciências práticas, a ética e a política, cujo objeto é o bem, que a ação procura expressar ${ }^{2}$.

Por sua vez, a phrónesis é a sabedoria prática, prudência, virtude intelectual que possibilita a intuição de valores éticos e a realização da excelência moral (BAILLY, A. op cit, p. 1020 e 2099)3․ É a inteligência racional que possibilita fazer boas escolhas, tomar boas decisões. Está associada à alma consciente, mas também à presença de espírito, a uma sabedoria que unifica razão e sentimento; uma sabedoria do coração, considerado, na tradição grega, como a sede de alma e o princípio da vida.

\section{O ponto de partida: Du texte à l'action}

Partindo dessa tradição, no escrito Du texte à l'action, publicado em $1986^{4}$ Ricoeur descreve a ação humana como um "poder fazer" (Id. Ibidem, p. 224.), uma "intervenção de um agente no curso das coisas" (Id. Ibidem, p.175), estabelecendo analogias entre a articulação significativa do fazer humano e a estruturação inteligível do acontecer, pelos textos.

A primeira formulação da teoria da ação por Ricoeur aparece ligada à problemática epistemológica da dialética entre o explicar e o compreender. Nela, uma nova proposta hermenêutica é estabelecida: o agir humano pode ser lido como um texto, isto é, "de um lado, a noção de texto é um bom paradigma para

1BAILLY, A. Dictionnaire Grec-Français. 26 Ed. Paris: Hachette, 1963, p. 1617.

2 PETERS, T.E. Termos filosóficos gregos. Lisboa: Gulbenkian, 1977, p.195. Ver Aristóteles. E.N, I, 136; 1094 a-b; E.N , III, 11116-1115 a.

3 Ver Aristóteles, E. N. VI e E.N. 11446.

4 RICOEUR, P. Du texte à l'action. Paris: Seuil, 1986. 
a ação humana, de outro, a ação é um bem referente para toda uma categoria de textos" (Id. Ibidem, p.175). Para assegurar essa afirmação, o pensador retorna o conceito de mythos, apresentado por Aristóteles na Poética, interpretando-o como imitação criadora da ação (Id, Ibid ) ${ }^{5}$. A ação sensata pode ser objetivada de modo análogo à fixação do discurso nos textos. Torna-se possível fazer essa objetivação graças às características da ação, análogas à "estrutura do ato da linguagem e que transforma o fazer em uma espécie de enunciação", separando "o significado a ação" do "acontecimento da ação" (Id. Ibidem, p.195). Ricoeur assinala que Anthony Kenny, em Ação, Emoção e Vontade, expôs a semelhança entre ação e o ato locucionário, pois ela tem um conteúdo proporcional possível de ser identificado, dado que verbos de ação constituem uma classe específica de predicados. As frases de ação têm uma complexidade de estrutura predicativa variável, que tipifica a estrutura proporcional da ação.

Austin e Searle também assinalaram a analogia entre o texto e a ação, mostrando (Austin) que "as diferentes classes de atos performativos de discurso descritas [em] Quando dizer é fazer, podem servir de paradigmas para as ações que preenchem atos da linguagem" (RICOEUR, P. op. cit. n.7, p. 192). Por sua vez, Searle evidenciou em Atos de linguagem, a possibilidade de estabelecimento de "uma tipologia da ação, conforme o modelo dos atos ilocucionários", bem como uma tipologia e uma criteriologia das regras constitutivas da linguagem e de ação (Id. Ibidem) ${ }^{7}$.

Na mesma obra Do texto à ação, Ricoeur examina dois conceitos éticos vinculados à teoria da ação: o de "razão de agir" e o "raciocínio prático". O primeiro conceito mostra que a ação é comunicável, é inteligível e que quatro traços caracterizam a noção de razão de agir. O primeiro traço é a motivação, presente no desejo, "condição mínima de inteligibilidade da ação sensata" (Id. Ibidem, p. 239). O segundo traço assinala que a ação deve ser explicável, isto é, que ela seja interpretável como exemplo de certa classe. O terceiro traço aponta que ela deve ser explicada por sua teleologia, pelo que visa intencionalmente, como assinalou Taylor ${ }^{8}$. O quarto traço indica que a ação supõe preferência racional, estabelecida pela razão deliberativa, a proairésis a que Aristóteles jáque se referia na Ética a Nicômaco (ARISTÓTELES, E. N. III ).

5 Ver também id. Temps et récit. vol. I. Paris: Seuil.

6KENNY, A. Action, Emotion and Will. Londres; Routledge e Kegan, 1963.

7 Ver também: AUSTIN, J. L. Quando dizer é fazer, P. Alegre: Artes Médicas, 1990; SEARLE, J. Os atos de linguagem. Ensaio de filosofia da linguagem; OLIVEIRA, M. A. de. Reviravolta linguístico-pragmática na filosofia contemporânea. S. P. Loyola, 1996; MARCONDES, D. A pragmática na filosofia contemporânea. RJ: Zahar, 2005.

8TAYLOR, C. The explanation of behavior. Londres: Routledge e Kegan, 1964. 
O raciocínio prático assim considerado aparece, diz Ricoeur, como herdeiro da tradição aristotélica.

Outro conceito importante é o de "regra da ação": só a ação humana é uma ação regrada, não apenas no plano da vida individual, mas também no da codificação da ação no âmbito da vida social, cultural. É a Geertz ${ }^{9}$ que o nosso filósofo recorre, referindo-se a modelos de significação, a símbolos que possibilitam a interpretação das condutas. Os códigos simbólicos permitem ler e avaliar as ações no horizonte de um contexto social.

Invocando novamente Aristóteles, Ricoeur lembra que a virtude presente nos comportamentos do homem justo tem como fundamento o raciocínio prático, expressão da phrónesis no plano da linguagem. Razão, cálculo verdadeiro e reto desejo: tudo constitui a razão prática. E já esboçando o que constituirá o eixo de sua "pequena ética", desenvolvida nas páginas de Si-mesmo como um outro ${ }^{10}$, reporta-se a Kant, mostrando que a norma - regra de ação - é um modelo do agir, uma orientação que assegura seu sentido.

O campo do agir é o mundo das coisas mutáveis; sua verdade é da ordem "do verossímil, no sentido de plausível e de provável” (Id. Ibidem, p. 250).

Em Si-mesmo como um outro, Ricoeur afirma que conjunto de textos aí apresentados envolvem uma ontologia do sujeito e têm como "unidade temática $o$ agir humano [...] a noção de ação adquire ao longo dos estudos, uma extensão e um concreção incessantemente crescentes" (Id. Ibidem, p. 31). Nessa obra, o agir é tratado como um modo de ser fundamental. Para nosso autor, o agir tem uma pluralidade de sentidos: é auto-designação de um sujeito falante; é o poder fazer, é imputação moral da ação ao sujeito.

Retomando as contribuições de Austin e da teoria dos atos da fala, de Searle, nosso filósofo afirma que "dizer é fazer, é em termos de ato que é preciso falar do dizer. Aí reside a intersecção maior com a teoria da ação [...] a linguagem se inscreve no próprio plano da ação" (Id. Ibidem, p. 58). A questão chave que emerge é "o enigma da relação entre a ação e o seu agente" (Id. Ibidem, p. 73), na meditação sobre quem age. Para Ricoeur, esse enigma implica a distinção entre o agir humano - que faz acontecer - e o acontecimento - que apenas ocorre.

O pensador aborda também a oposição entre motivo/causa da ação e a noção de intenção, que fornece razões de agir. Os autores em que se apóia para levar a efeito essas discussões são, do lado da filosofia de expressão inglesa: Danto,

9 GEERTZ, C. The interpretation of cultures. Nova Iorque: Basic Books, 1973.

10 RICOEUR, P. Du texte à l'action, p. 249; id. Soi-même comme un autre. Paris: Seuil, 1990. 
Hampshire, Anscombe, Davidson. O fulcro da meditação é a análise conceitual da ação e o estudo do que caracteriza as ações ditas intencionais. Procura evidenciar que seu fundamento é a razão de agir, conhecimento prático que considera a relação entre a ação e o agente. A intenção funciona como um motivo prospectivo, um impulso em direção ao futuro.

Partindo da ontologia do acontecimento proposta por Davidson ${ }^{11}$, Ricoeur conduz sua análise pela via que relaciona intenção e ação. A ação se distingue dos outros eventos pela intenção; os outros eventos apenas acontecem; a ação faz acontecer"12. Diz nosso filósofo: "descrever uma ação como tendo sido feita intencionalmente, é explicá-la pela razão que o agente teve de fazer o que fez" (Id. Ibidem, p. 95). Nosso autor propõe explicações teleológicas, dizendo que quando algo acontece, porque foi visado por alguém como um fim, "este evento foi requerido por esse fim", como também afirma Taylor, citado por Ricoeur ${ }^{13}$.

Mais ainda: a fenomenologia da ação mostra que a explicação teleológica da ação por um fim deve ser completada pela explicação que acrescenta à primeira a noção de orientação "consciente, de um agente capaz de ser reconhecer como sujeito de seus atos"14.

Afirmando essas teses, o pensador francês põe em relevo que as ações intencionais são regidas por leis, e mostra que essas leis não são mecânicas, mas supõem escolha e orientação (Id., ibid) por parte do sujeito. O laço entre ação e agente não pode nunca ser deixado de lado, mesmo que não seja tematizado, diz Ricoeur.

Criticando Davidson, cuja “ontologia dos acontecimentos, fundada num tipo de análise lógica das frases de ação [...] está condenada a ocultar a problemática do agente enquanto possuidor da ação [...]” (Id. Ibidem, p. 106), Ricoeur relaciona a problemática da ação à "de imputação de ação a seu agente" (Id. Ibidem, p. 107). É à luz da meditação sobre o agente, sujeito no qual estão presentes a ipseidade e a mesmidade, que nosso filósofo examina "a noção de ascrição da ação ao agente" (Id. Ibidem), e seu laço com a atestação. Essa reflexão perpassará o quarto estudo de Si-mesmo como um outro.

Recorrendo novamente a Aristóteles, na Ética a Nicômaco, livro III, o pensador francês mostra que, para a o Estagirita, a ação depende do agente. Mostra também que segundo Aristóteles, a ação pode ser feita de bom ou de mau gra-

11 DAVIDSON, D. Essays on actions and events. Oxford: Clarendon Press, 1980.

12 RICOEUR, P. Soi-même comme un autre, Paris: Seuil, p. 94.

13 TAYLOR, C. The explanation of behavior. Londres: Routledge e Kegan, 1964.

14RICOEUR, P. Soi-même comme un autre. Paris: Seuil, p. 99 
do, exprimindo uma escolha preferencial (proairésis), que precede e determina a deliberação (bouleusis). A dependência da ação para com um agente põe em relevo a dimensão ética da determinação do agir. É a escolha que torna o homem bom ou mau, exemplificando seu caráter. A razão disso é a atribuição da ação ao agente, posta em evidência pelo filósofo grego quando afirma que o homem é pai de suas ações, senhor de seus atos, responsável pelo que faz.

Nas teorias da ação contemporânea, a ascrição - vinculação da ação ao agente - tem "um significado distinto de atribuição" (Id. Ibidem, p. 116. O grifo é nosso). Ricoeur examina as teses de Strawson, Hart, Danto, com vistas a estudar o significado atual de noção de ascrição.

Strawson afirma que "as características físicas e psíquicas, pertencem à pessoa" que dispõem delas, "as possui" (Id. Ibidem). Assim a ação pertence a alguém; a intenção que a move é de alguém; donde Ricoeur dizer que "a ascrição consiste [...] na reapropriação pelo agente de sua própria deliberação" (Id. Ibidem, p. 117), pois decidir é assumir uma opção como própria.

A noção de ascrição, assim considerada, faz surgir, contudo, na opinião de Ricoeur, três aporias. A primeira surge das teses de Strawson, que afirma que os predicados práticos, assim como os psíquicos, têm como característica serem atribuíveis a si e a outrem, de modo análogo. Para Ricoeur, "o desdobramento da ascrição entre si mesmo e um outro sugere" (Id. Ibidem, p.119) que a atribuição da ascrição a alguém possa manter-se em suspensão, sendo compreendido seu sentido "fora de toda atribuição explicita" (Id. Ibidem). Como isso é possível? É essa a questão aporética, diz Ricoeur. Para que a ascrição assim compreendida seja possível, é preciso, diz nosso filósofo, "que um agente possa designar a si mesmo, de tal modo que exista um outro verdadeiro a quem a mesma atribuição seja feita de modo pertinente" (Id. Ibidem, p. 121). Para que isso possa ocorrer, é necessário abandonar a semântica da ação e assumir a perspectiva da pragmática, "que leva em conta as proposições, cujo significado varia segundo a posição do sujeito falante [...]" (Id. Ibidem).

É essa passagem que desencadeia o surgimento das outras aporias da ascrição, segundo o nosso autor. A segunda aporia refere-se ao estatuto de distinção ascrição, descrição, prescrição. Hart propõe identificar imputação (o agente é responsável por suas ações) e ascrição. Daí resulta uma ruptura completa entre as noções de ascrição e descrição. Hart assimila a ascrição à imputação moral e jurídica, fazendo da imputação "a forma forte de uma estrutura lógica, da qual a ascrição seria a forma fraca” (Id. Ibidem, p. 122. O grifo é nosso). Ricoeur, embora reconheça a relevância da tese de Hart, assinala as dificuldades da apro- 
ximação entre imputação e ascrição, por várias razões. A primeira deve-se à complexidade das ações a que a imputação se refere em contraste com as ações simples que a gramática e a lógica das frases de ação descrevem; a segunda razão é que os enunciados jurídicos e morais se referem a ações criticáveis e presumíveis; ora, a ascrição parece preceder qualquer enunciado acusativo conforme bem mostrou, diz Ricoeur, Aristóteles na Ética a Nicômaco, quando o estagirita faz preceder "sua teoria das virtudes por um ato fundamental, a escolha preferencial, no qual se expressa uma potência de agir mais primitiva que o caráter criticável ou louvável [...] da ação produzida" (Id. Ibidem, p. 123). Ao referir o problema da ação a uma capacidade do homem, a potência de agir, Ricoeur aponta, na Ética a Nicômaco, a dimensão ética da referência ao locutor, entendido como um sí, e do interlocutor, compreendido como um outro, diverso do sí (Id. Ibidem, p. 123-124).

A terceira aporia ligada à identificação entre a imputação e ascrição, diz respeito à compreensão do significado da potência de agir. Ricoeur mostra que "dizer que uma ação depende de seu agente é dizer, de modo equivalente, que ela está em seu poder" (Id. Ibidem, p. 124).

A proposta de nosso autor é pensar a intervenção do homem no mundo, conjugando os elementos da ação: quem a faz, por que ela é feita, através de que ela é feita. O que o filósofo pretende é mostrar que a atestação do poder fazer tem uma face epistemológica e outra face ético-ontológica, a qual remete a uma decifração do sí, decifração do homem. É no horizonte da meditação sobre mesmidade e identidade, que se inscreve a compreensão do agir como expressão do sí, da ipseidade, da identidade.

A existência humana se expressa no poder fazer, mas também no narrar, dizer, imputar, descrever, prescrever, estabelecendo "um laço específico entre a constituição da ação e a constituição do sí"15. É discutindo esse laço que o pensador francês aprofunda a noção de identidade narrativa, já esboçada em Tempo e Narrativa III. O objetivo da ação é a realização plena de sí, o bem-viver. E é a lição de Ética a Nicômaco que Ricoeur invoca, para ancorar na ação a busca da vida boa (Id. Soi-même comme un autre, p. 203, nota 1). Afirma também uma correlação entre práxis e poiésis, quando assegura que a ação "deve ser poiésis em vista de ser práxis" (Id. Ibid., p. 206-207; nota 2)

15 Id. Temps et récit. Paris: Seuil, 1985, vol III. Ver também nosso Le même et l'autre: une perpective sur la notion de personne chez Paul Ricoeur. In Le même et l'autre. Actes Du XXXI Congrès International de l'ASPLF. Budapest: SHPLF/ Univ. ELTE, 2009, p. 379-386. 
É nesse sentido que Abel $^{16}$ fala de uma poética da ação, do livre jogo de possibilidades e alternativas de ser, que Ricoeur sintetiza em uma filosofia do homem capaz, entendida como filosofia do agir e do sentir. Essa reflexão pensa a ação segundo uma regra do agir, segundo a phrónesis, a sabedoria prática. $\mathrm{O}$ agir é então pensado "como a faculdade de começar, de fazer acontecer algo" (Id. Ibidem, p. 23), em vista da refiguração das possibilidades da existência, da reabertura, a cada momento, de novas possibilidades de ser no mundo. É também nesse sentido que Ricoeur fala da aproximação, entre phrónesis e aísthesis no livro VI da Ética a Nicômaco, ao se referir à atestação, "quando a certeza de ser o autor de seu próprio discurso e de seu próprio discurso e de seus próprios atos se torna convicção de julgar bem e agir bem, numa aproximação provisória do bem-viver" (RICOEUR, P. Soi-même comme un autre, p. 211). As ações humanas tendem para um fim e o trabalho de interpretação de ação e de sí está vinculado à adequação, sempre provisória, entre o ideal de vida boa e as decisões e escolhas de nossa existência individual. A noção de sabedoria prática é central na discussão ricoeuriana do problema do agir. Sabedoria prática implica a deliberação complexa, que diz respeito à capacidade de discernir o que é bom para sí e para a obtenção da vida feliz.

\section{Um texto chave: À la gloire de la phronèsis}

Um texto publicado em 1997, reunindo estudos apresentados por ocasião de seminário e colóquio da Academia de Versalhes, aborda o livro VI da Ética a Nicômaco ${ }^{17}$. Ricoeur contribui com um trabalho intitulado: "À glória da phrónesis"18.

Nesse texto, nosso filósofo começa apresentando a tradução habitual do conceito de phrónesis pelo equivalente latino prudentia, prudência, sabedoria prática e assinalando as retomadas contemporâneas do conceito, entendido como "sabedoria dos limites" por Pierre Aubenque. Assinala também as interpretações de Gadamer, MacIntyre, D. Ross, W. F. R. Hardie, D. Wiggins, Gauthier-

16ABEL, O. Une poétique de l'action. in VV.AA. L'homme capable. Autour de Paul Ricoeur. Paris: PUF/Collège International de Philosophie, 2006, p. 13-26.

17 CHATEAU, J.-Y. (org.) La verité pratique. Aristote. Éthique à Nicomaque. Livre VI. Paris: Vrin. 1997.

18RICOUER, P. À la gloire de la phronesis. (Éthique à Nicomaque, livre VI). in CHATEAU, J.-Y. (org) op. cit.,pp. 13-22. 
Jolif $^{19}$, pondo em relevo a contraposição entre a tradução do termo de um ponto de vista teleológico (meio-fim) e deontológico (regra/caso).

O problema da phrónesis é o da ação sensata, inseparável do homem sábio ou prudente, capaz de reconhecer a regra correta (orthos logos), a reta razão que orienta a disposição e o desejo, tornando-os razoáveis. Outros conceitos associados à phrónesis são as noções de justo meio e regra correta, em função de um fim visado. No mundo contingente, a prudência é a disposição para agir bem, segundo uma reta razão, discernindo o que é bom para o homem. Caracteriza-se pela "deliberação, consideração do bem pessoal e do bem comum, a perspectiva da vida feliz, o exame do contingente, o discernimento do que é bom ou mau para o homem"20.

Na Ética a Nicômaco, Aristóteles distingue as virtudes éticas das dianoéticas; Ricoeur mostra que a oposição meio-fim, regra-caso, que caracterizam sua expressão, achamse nos livros III e VI. A conciliação entre ambas, virtudes éticas e dianoéticas, dá-se quando constata que a phrónesis é inseparável do phrónimos (homem sábio); é nele que a unidade entre os dois tipos de virtude se mostra como ligação entre o orthos logos, a reta razão, e o desejo, quando subordinado à razão.

Os neo-aristotéticos contemporâneos afirmam, diz Ricoeur, o "enraizamento das virtudes intelectivas nas virtudes do caráter" (Id. Ibidem, p. 16), relacionando as noções de verdade, sabedoria, conhecimento, através da arte de produzir a verdade, no mundo contingente. A unidade, no juízo intelectivo, da apreensão perspicaz e da deliberação correta, está presente no conceito de phrónesis e desencadeia, na filosofia contemporânea, a reavaliação do conceito, desdobrando e explicitando suas implicações.

O retorno a Aristóteles na meditação atual sobre a sabedoria prática tem, diz Ricoeur, duas conotações. Uma conotação negativa, que consiste na recusa, no meio anglo-saxão e no meio europeu, "tanto do formalismo kantiano quanto do empirismo" (Id., ibid., p. 210), de que os trabalhos de MacIntyre seriam o exemplo típico. Na linhagem desencadeada pelo Krisis, de Husserl, o Sein und Zeit, de Heidegger e o Warheit und Methode, de Gadamer, expressariam a crí-

19 GADAMER, H.G. Warheit und Methode, Tübingen. C.B. Mohr, 1990; MACINTYRE, A. After Virtue. University of Notre Dame Press, 1981; ROSS, D, Aristotle. Londres, 1923; HARDIE, W.F.R. Aristotle's Ethical Theory. Cap. XI: Practical Wisdom. Oxford: Claredon Press, 1980; WIGGINS, D. Deliberation and Pratical Reason, in RORTY, A. O. Essays an Aristotle's Ethics. University of California Press, 1980, pp. 221-240; GAUTHIER-JOLIF (Trad.). Aristote. Ethique à Nicomaque. Louvain/Paris: Nauwelaerts, 1970.

20RICOUER, P. À la gloire de la phronesis, p. 18.Ver também ARISTÓTELES, E. N., 1140b-45. 
tica da subordinação das ciências humanas ao modelo das ciências da natureza, assim como a proposta de uma nova ética (Id. Ibidem, pp. 21- 22). A conotação positiva se mostra como valorização da atividade criadora do homem e da equidade; como ênfase na argumentação que considera a lógica do provável e como "enraizamento da reflexão filosófica numa prática prévia, numa cultura viva [...]", de que a teoria da justiça de Rawls, a ética da discussão de Apel e Habermas, as teses de Taylor em The Sources of Self seriam os exemplos exponenciais (Id. Ibidem, p. 22) ${ }^{21}$.

Na meditação de Ricoeur acham-se integradas as contribuições mais importantes da volta a Aristóteles na filosofia contemporânea. Essa integração, síntese superadora das aporias e dos conflitos entre correntes filosóficas diversas, resulta na formulação de uma ética, atenta às discussões contemporâneas sobre o problema do agir e sobre a sua validação ética, que deve buscar, num mundo complexo e plural, novos critérios de verdade. A formulação acabada dessa ética acha-se na última obra publicada por Ricoeur, Percurso do reconhecimento ${ }^{22}$, na qual o tema reaparece, aprofundado de modo original e instigante. Na sua última obra o mestre oferece um modelo de investigação, que será inspirador durante muito tempo. Elogio da dimensão ética da existência, fundada no reconhecimento de sí e no respeito e amor ao outro, refaz a busca sempre inconclusa da justiça e da paz.

21 Id. Ibidem, p. 22. Ver também BERTI, E.Aristóteles no século XX. SP: Loyola,1997 22 Id., Parcours de la reconnaissance. Paris: Stock, 2004.

\section{Referência Bibliográfica}

ABEL, O. Une poétique de l'action. In: VV.AA. L'homme capable. Autour de Paul Ricoeur. Paris: PUF/ Collège International de Philosophie, 2006, pp. 13-26.

ARISTÓTELES, Obras. Madri: Aguilar, 1967. Éthique de Nicomaque. Paris: Garnier/ Flammarion, 1965.

AUSTIN, J. L. Quando dizer é fazer. Porto Alegre: Artes Médicas, 1990.

BAILLY, A. Dictionnaire Grec-Français. 26a . Ed. Paris: Hachette, 1963.
BERTI, E. Aristóteles no século XX. São Paulo: Loyola,1997.

CHATEAU, J.-Y. (org.) La verité pratique. Aristote. Éthique à Nicomaque. Livre VI. Paris:Vrin. 1997.

DANTO, A. Analytical Philosophy of Action. Cambridge: Cambridge University Press, 1973.

DAVIDSON, D. Essays on actions and events. Oxford: Clarendon Press, 1980.

HEIDEGGER, M. Sein und Zeit. Tübingen: Max Niemeyer, 1993; trad. Brasil. Ser e Tempo, vols. 1 e 2. Petrópolis: Vozes, 1988 e 2005. 
HUSSERL, E. A crise das ciências europeias e a fenomenologia transcendental. Lisboa: Centro de Filosofia da Universidade de Lisboa, 2008.

GADAMER, H. G. Warheit und Methode. Tübingen. C. B. Mohr, 1990; trad. brasileira Verdade e Método. Petrópolis: Vozes.

GEERTZ, C. The interpretation of cultures. Nova Iorque: Basic Books, 1973.

GAUTHIER-JOLIF (Trad.). Aristote. Éthique à Nicomaque. Louvain /Paris: Nauwelaerts, 1970.

HARDIE, W. F. R. Aristotle's Ethical Theory. Cap. XI: Practical Wisdom. Oxford: Claredon Press, 1980.

KENNY, A. Action, Emotion and Will. Londres: Routledge e Kegan, 1963.

MACINTYRE, A. After Virtue. University of Notre Dame Press, 1981.

MARCONDES CESAR, C. Le même et l'autre: une perpective sur la notion de personne chez Paul Ricoeur. IN: Le même et l'autre. Actes Du XXXI Congrès International de l'ASPLF. Budapest: SHPLF/ Univ. ELTE, 2009, p. 379-386.

Crise e liberdade em Merleau-Ponty e Ricoeur. Aparecida: Ideias e Letras, 2011.

MARCONDES, D. A pragmática na filosofia contemporânea. Rio de Janeiro: Zahar, 2005.

OLIVEIRA, M. A. de. Reviravolta linguísticopragmática na filosofia contemporânea. São Paulo: Loyola, 1996.

PETERS, T. E. Termos filosóficos gregos. Lisboa: Gulbenkian, 1977.

RICOEUR, P. Du texte à l'action. Paris: Seuil, 1986. Temps et récit. vol. I. Paris: Seuil.

.Soi-même comme un autre. Paris: Seuil, 1990. . À la gloire de la phronesis. (Éthiqueà Nicomaque, livre VI) IN: CHATEAU, J.-Y. (org) op. cit., pp. 13-22. .Parcours de la reconnaissance. Paris: Stock, 2004.

RORTY, A. O. Essays an Aristotle's Ethics. University of California Press, 1980.

SEARLE, J. R. The Philosophy of Language. Oxford: Oxford University Press, 1977.

TAYLOR, C. The explanation of behavior. Londres: Routledge e Kegan, 1964.

WIGGINS, D. Deliberation and Pratical Reason. IN: RORTY, A. O. Essays an Aristotle's Ethics. University of California Press, 1980, pp.221-240. 